\title{
Neuroscience grows in China
}

\author{
Neuroscience has reached critical mass in Shanghai and Beijing, attracting substantial financial support and \\ enticing Western-trained scientists to return to China. Now it is time for the bounty to spread to the provinces.
}

$\triangle 1$ fter two decades of economic boom, China has rededicated itself to science. Neuroscience has benefited immensely, as anyone reading the literature cannot fail to notice. Much of this progress has been driven by a small group of foreign-trained scientists who have paired up with institutes in China, and, from the secure vantage point of tenured positions in the United States, taken on the Chinese bureaucracy to inject previously unthinkable measures of scientific independence and competitiveness.

The Institute of Neuroscience in Shanghai, founded in 1999 and led by Berkeley's Mu-ming Poo, has inspired reform of existing institutions and the establishment of newer ones. The National Institute of Biological Sciences, opened in 2004 on the outskirts of Beijing and led from afar by Xiaodong Wang of the University of Texas Southwestern, is modeled on the Howard Hughes Medical Institute. It provides generous support to promising scientists without prescribing projects or approaches, in diametric contrast to the applied science traditionally favored by Chinese 15-year plans, which still account for the majority of available research funds. Merit is determined by performance reviews involving international scientific boards, another concept that is new to Chinese science.

These institutes and the venerable elite institutions in Beijing and Shanghai attract successful Chinese neuroscientists from overseas. The current US funding crunch helps, but so does Chinese generosity through programs such as the Chinese Academy of Science's Hundred Talents Plan, the Natural Science Foundation of China's Outstanding Young Scientist program and the Changjiang Professorship from the Ministry of Education.

Along with ample funds, Chinese-born neuroscientists are attracted home by smart and eager students. Building on a long tradition of learning and scholarship, students must score brilliantly in rigorous examinations to be admitted to the best universities. Millions take the exams, so graduate programs and institutes have access to many motivated students. In the United States, it takes years of successful work to build a large group, whereas this can happen much more quickly in China.

Once they are at an elite Chinese institution, many graduate students set their sights on moving to the West, particularly the United States. In recent years, the United States has issued more than 20,000 visas annually to Chinese students across all fields. Yi Rao, who returned in August to become Dean of Life Sciences at Beijing University after an illustrious career in the United States, notes that about $50 \%$ of the applications to the neuroscience graduate programs at Washington University and Northwestern University come from mainland China. Certainly, the impact of Chinese students and postdocs in US neuroscience labs is considerable.

Few of these students, however, come home to China, resulting in a substantial loss of talent to their country. As opportunities have increased, the elite institutions have become increasingly selective. Liqun Luo of Stanford University believes that attractive positions in Beijing and Shanghai are now no less competitive than US tenure-track jobs.

China, of course, is much bigger than just Beijing and Shanghai. The universities of provincial capitals, cities with millions of inhabitants and tens of thousands of students, still await the influx of modern life sciences. Several provinces have now committed funds. Bai Lu of the US National Institute of Child Health and Human Development thinks that promising neuroscience programs are budding in Xi' an (Shaanxi province in central China), Guangzhou (the southern Guangdong province) and Chengdu (southwestern Sichuan province).

Developmental neurobiologist Huashun Li was lured to Sichuan University in Chengdu by generous start-up funds, motivated students and the promise that he could build a vigorous research environment. After spending 16 years in the United States, from his $\mathrm{PhD}$ studies through the establishment of his own lab at the Medical College of Georgia, he became director of a newly established West China Institute of Developmental and Stem Cell Biology at Sichuan University's Women's and Children's Hospital in October. Li cherishes the opportunity to build an institute managed in the Western style from scratch. He plans to populate his new institute with Western-trained returnees and has already convinced Changan Jiang, trained at Caltech and UCLA, to join him. He hopes to fill five positions in five years and to eventually expand the institute to at least 15 investigators. Like nearly all Chinese neuroscientists, in China or the United States, he is convinced that the authorities' commitment to basic life sciences will last.

Apart from personal reasons, what keeps Chinese expatriate students and postdocs from returning? Li says that in Chengdu, as elsewhere in China, he faces an inefficient administrative system, keenly feels the absence of ambitious peers and needs to work hard to foster the critical thinking that is so crucial to the scientific enterprise, although he feels that the situation will improve as more talented scientists return. Bai Lu, who has resisted entreaties to return, cites the remaining preference of Chinese politicians for centrally planned 'big science' projects, and says that more money needs to be distributed through investigator-driven competitive grant mechanisms. He also emphasizes that inspiration from colleagues is crucial. Institutes in the Chinese provinces have a long way to go to establish critical mass in this regard. Visionary leadership is lacking, says Lu, who believes that the recent return of Yi Rao from an endowed US professorship may inspire other Chinese-born neuroscience leaders to consider returning. Neuroscience grew strong in Beijing and Shanghai largely as a result of the dedication and hard work of a few prominent individuals. Similar personal commitments may be needed to establish neuroscience in the provinces. 